\title{
PHENYLPROPANOIDS, EUGENOL SCAFFOLD, AND ITS DERIVATIVES AS ANTICANCER
}

\author{
FADILAH FADILAH $^{1,2}$, ARRY YANUAR ${ }^{1}$, ADE ARSIANTI $^{2}$, RETNOSARI ANDRAJATI $^{1}$
}

${ }^{1}$ Department of Pharmaceutical Chemistry, Faculty of Pharmacy, University of Indonesia, Depok Beji, Indonesia. ${ }^{2}$ Department of Medical Chemistry Faculty of Medicine, University of Indonesia, Jalan Salemba Raya 6 Jakarta 10430, Indonesia. Email: fadilah81@gmailcom

Received: 08 November 2016, Revised and Accepted: 30 November 2016

ABSTRACT

Eugenol (EU) is a phenylpropene, an allyl chain-substituted guaiacol. EU is a member of the phenylpropanoids class of chemical compounds. It is a colorless to pale yellow oily liquid extracted from certain essential oils especially from clove oil. Further, chemopreventive agents might be used singly or in combination with chemotherapy or radiotherapy for the more effective treatment of cancer by enhancing the efficacy of these modalities with minimal side effects and toxicity. Considering that EU scaffold may be a prospective chemopreventive agent, its potent antitumor ability to interfere with solid cancer cell growth and its molecular mechanism were evaluated as an initiative toward the development of a novel strategy for cancer treatment. This review article will conduct that EU as the antiproliferative activity and molecular mechanism of the EU induced apoptosis against the cancer cells and animal models.

Keywords: Eugenol, Derivatives of eugenol, Scaffold, Anticancer, Phenylpropanoids.

(c) 2017 The Authors. Published by Innovare Academic Sciences Pvt Ltd. This is an open access article under the CC BY license (http://creativecommons. org/licenses/by/4. 0/) DOI: http://dx.doi.org/10.22159/ajpcr.2017.v10i3.16071

\section{INTRODUCTION}

Apoptosis is a key hallmark of cancer [1]. In general, cells can die by apoptosis, a form of programed cell death. The activation of proapoptotic factors, resistance to apoptosis is often due to upregulation of antiapoptotic factors. Thus, a number of genes that encode components of the apoptotic machinery are directly targeted by activating or inactivating genetic lesions in cancer cells. It is accompanied by various morphological changes such as nuclear condensation and fragmentation, isolation of cytoplasmic organelles into discrete regions, formation of surface membrane and fragmentation of the dead or dying cell into membrane-bound bodies [2]. The Bcl-2-protein family regulates cell death and proliferation $[3,4]$, two processes dysregulated during oncogenic transformation. Thus, it is not surprising to find an upregulation of Bcl-2 expression in many cancers, including chronic lymphocytic leukemia Bcl-2 is highly expressed at the onset of many cancers [3-5]. In addition to B-cell lymphomas [6], Bcl-2 has been implicated in solid tumors [7] and non-small cell lung cancer [8]. The antiapoptotic Bcl-2-proteins are highly promising targets for the development of novel anticancer treatments.

To prevent such degenerative diseases, natural and synthetic drugs have gained significant attention. Used the synthetic drugs, natural phytochemical compounds and drugs based on monoclonal antibody. Chemically synthesized anticancer drugs have toxic side effects and usually cause potential damage to normal cells. Antitumor activity has been reported for essential oils against several tumor cell lines [9-11], and these oils contain a high percentage of phenylpropanoids. The phenylpropanoid pathway is responsible for the biogenesis of several structurally diverse groups of compounds. Many phenylpropanoids have the potential to act as antioxidants, modulate the activity of cytochrome P450 and the enzymes in the arachidonic acid cascade, activate phase II reactions and affect cell signaling. In vitro many have been shown to inhibit bacterial and viral replications [12]. This compounds with scaffold phenylpropanoids including Eugenol (EU), flavonoids, catechins, gingerol, coumarins, plant sterols, and phytoestrogens have a variety of therapeutic properties ranging from antibacterial and antiviral, and ability to protect against heart disease and various cancers [12]. The scaffold phenylpropanoids, which are believed to contribute to their pharmacological activity [13]. Phenylpropanoids scaffolds, such as thiosemicarbazones and coumarin, can inhibit topoisomerase II enzyme. The anticancer activities of thiosemicarbazones were closely related to the parent aldehyde or ketone group and terminal amino substitution [14]. Coumarin derivatives with compounds 3, 6-dibutyl7-hydroxy-4-oxo-2-chlrobenzyl -4H chromene -8- carbaldehyde are excellent promoters of N-acetyltransferase 2 inhibitor [15]. EU shows better application potential in the prevention and treatment of some cancers. The anticancer activity of EU has become an important research topic in recent years.

EU 1 and its derivatives have been reported to inhibit colon cancer cell proliferation by arresting the cells in sub G1 phase, augment reactive oxygen species (ROS) levels that result in DNA fragmentation, which is a hallmark of apoptosis. It has been reported that EU is a phenolic compound that induces apoptosis in human colon cancer cells [16]. The antiproliferative activity of EU against melanoma [17], leukemia [18], gastric [19], skin tumor [20], and prostate cancer [21] cells has been confirmed by many researchers. Structure of phenylprepanoids, eugenol scaffold and its derivatives as anticancer as Fig. 1. while the related research on phenylprepanoids, eugenol scaffold and its derivatives as anticancer as Table 1.

\section{ANTICANCER ACTIVITY OF PHENYLPROPANOIDS, EU SCAFFOLD AND ITS DERIVATIVES}

Activity of phenylpropanoids, EU scaffold and its derivatives against colon cancer

Colorectal cancer is the second most common malignancy in women and the third in men worldwide with an increasing incidence. In addition, colorectal cancer is the fourth common cause of death from cancer. Even if advances in drug development and surgery led to an increased overall survival, the prognosis of patients with metastasized colorectal cancer is still limited [22]. The treatment of colorectal cancer with EU resulted in reduction of intracellular non-protein thiols and increase in the earlier lipid layer break. Further events like dissipation of matrix metalloproteinases (MMP) and generation of ROS were accompanied in the EU induced apoptosis. ROS generation resulted in the DNA fragmentation of treated cells as shown by DNA fragmentation 
and TUNEL assay. Further activation of p53 and caspase-3 was observed in Western blot analyses. The results demonstrated molecular mechanism of EU -induced apoptosis in human colon cancer cells. This research will further enhance EU as a potential chemopreventive agent against of colon cancer [16]. Another research was conducted that EU combine with canola oil showed an antiproliferative effect against colon cancer cell lines depending on the concentration and the cell lines used. Further EU with canola oil exhibited lower IC50 values against both cell lines compared to EU 1 both EU and EU with canola oil induced sub G1/S cell cycle arrest and apoptosis via ROS-dependent mechanism. Thus, results suggest that EU 1 and EU with canola oil have similar antiproliferative mechanisms against colon cell lines. Therefore, this research further enhances EU as a potential chemopreventive agent against colon cancer. In future, mechanism of intracellular induced ROS that triggers apoptosis will be considered [23]. Other study conducted with bi EU (magnolol) 2. This results of the study have shown that magnolol 2 downregulated expression of the antiapoptotic protein Bcl-2, upregulated expression of pro-apoptotic protein p53 and Bax, and caused the release of mitochondrial cytochrome c. Magnolol 2 induced p53 and Bcl-2 expression was abolished in the presence of magnolol compound. Magnolol inhibited migration and invasion of HCT-116 cells through AMPK activation [24]. These findings demonstrate that AMPK mediates the anticancer effects of magnolol through apoptosis in HCT-116 cells. Several researchers have shown that magnolol inhibits proliferation and induces apoptosis in cancer cells by inhibiting DNA synthesis [25], signaling pathway as well as Ras/Raf-1/Erk actions [26]. However, it remains to be determined whether apoptotic cell death is associated with the AMPK signaling pathway in HCT-116 colon cancer cells treated with magnolol.

\section{Anticancer activity of phenylpropanoids, EU scaffold and its derivatives against breast}

Breast cancer remains a worldwide public health concern and a major cause of morbidity and mortality among females [27]. Many studies have proved that EU 1 upregulated the versatile cyclin-dependent kinase inhibitor p21WAF1protein, and inhibited the proliferation of breast cancer cells in ap53-independent. These antiproliferative and pro-apoptotic effects were also observed in vivo in xenografted human breast tumors [28].

Faatma et al. [29] conducted that derivatives EU potent to inhibitory activity against MDA-MB-231 cell migration at the 1-4 IM dose range. The derivatives EU with $\mathrm{Z}$ isomers compound 3 and 4 were more active as invasion inhibitors compared to their structurally related $\mathrm{E}$ isomers 5 and 6 . The cytotoxic activities of compounds 3, 4 against two breast cancer cell lines MDA-MB-231 and human cancer cell-7 (MCF-7) were evaluated. Anti-invasive activity of the semisynthetic derivatives is not due to a direct cytotoxic effect on MDA-MB-231. Compound 3,4 may promote their anti-invasive activity through the induction in cell morphology.

Another study observed that EU could suppress breast cancer cell migration which was mediated mainly through decreasing the MMP-9 and paxillin gene expression. EU could inhibit cell proliferation and migration of MCF-7 cells dose and time dependently. On the other hand, EU-treated cells displayed condensed and fragmented nuclei compared to the control group [30]. Effect of EU on intracellular redox status of the human breast cancer cells was assessed by determining the level of glutathione and lipid peroxidation products. EU treatment inhibited the growth and proliferation of human MCF-7 breast cancer cells through induction of cell death, which was dose and time dependent. Microscopic examination of EU treated cells showed cell shrinkage and apoptotic body formation. Further, EU treatment also depleted the level of intracellular glutathione and increased the level of lipid peroxidation. The dose-dependent increase in the percentage of apoptotic cells and DNA fragments suggested that apoptosis was involved in EU-induced cell death and apoptosis have played a role in the chemopreventive action of EU [31].
Anticancer activity of phenylpropanoids, EU scaffold and its derivatives against cervical cell

Cervical cancer is caused by human papillomavirus infection. Most human papillomavirus infection is harmless and clears spontaneously, but persistent infection with high-risk human papillomavirus (especially type 16) can cause cancer of the cervix, vulva, vagina, anus, and oropharynx. The virus exclusively infects epithelium and produces new viral particles only in fully mature epithelial cells. Human papillomavirus disrupts normal cell-cycle control, promoting uncontrolled cell division, and the accumulation of genetic damage [32]. Hemaiswarya et al.'s [33] study of combination of phenylpropanoids 7 with 5-fluorouracil as anticancer agents against human cervical cancer (HeLa) cell line. The study they observed that cytotoxic activity of phenylpropanoid scaffold was in the order of EU $1>$ ferulic $8>$ cinnamic $9>$ caffeic $10>$ chlorogenic $11>$ p-coumaric $12>3$,4-dimethoxycinnamic $13>2,4,5$-trimethoxycinnamic acids 14 . EU and ferulic, cinnamic and caffeic acids exhibited synergy with 5 -fluorouracil. Synergy between compounds arises because of their different modes of action. There was a significant increase in the number of apoptotic cells in the combination when compared to the individual treatments. Treatment with a combination of 5-fluorouracil and EU increased the number of cells in the G0/G1 and G2/M phase when compared to control. An increase in cells in the sub-G1 phase was also observed. Another research conducted that EU showed dose-dependent selective cytotoxicity toward HeLa cells in comparison to normal cells, pointing to its safe cytotoxicity profile. A combination of EU and gemcitabine induced growth inhibition and apoptosis at lower concentrations, compared with the individual drugs. The analysis of the data using a combination index $(\mathrm{CI})$ showed $\mathrm{CI}$ values of $<1$ indicating strong synergistic interaction. In addition, the expression analysis of genes involved in apoptosis and inflammation significant downregulation

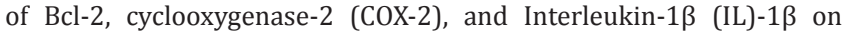
treatment with EU. The results suggest that EU exerts its anticancer activities via apoptosis induction and anti-inflammatory properties and provide demonstrated synergic between EU and gemcitabine, which enhance the therapeutic index of prevention and/or treatment of cervical cancer [34].

Several research studies to treatment combinations sulforaphane and EU induces differential effects on human cervical cancer cells. Treatment $\mathrm{EU}$ and sulforaphane with variable dose resulted in differential effects with an antagonistic effect at lower and synergistic at higher sublethal doses as reflected in cell cytotoxicity and apoptosis induction. Importantly, gemcitabine used in conjunction with the low- and high-dose combinations showed no significant cell death at lower doses suggesting that cell cytotoxicity is proportional to gemcitabine alone, whereas at higher sub-lethal doses of sulforaphane and EU, it was found to act in a synergistic with gemcitabine. Furthermore, sulforaphane and EU combinations at synergistic dose significantly downregulated the expression of Bcl-2, COX-2, and IL- $\beta$ but not the antagonistic combinations [35]. Another study was conducted of effect hydroxychavicol 17 and its analogs 18 with significant anti-proliferative activity in the micromolar range in HeLa cell line. From the 15 novel hydroxychavicol analogs with varying anti-proliferative activities in cervical cancer cell lines that show very encouraging results compared to the parent compounds [36].

\section{Anticancer activity of phenylpropanoids, EU scaffold and its} derivatives against melanoma

Malignant melanoma arises from the malignant transformation of epidermal melanocytes due to both environmental and genetic factors [37]. Melanoma is the most rapidly increasing malignancy in the white population [38]. Arung et al., 2011, were observed that EU and EU acetate 19 were isolated as the active compounds showed melanin inhibition of $60 \%$ and $40 \%$ in B16 melanoma cell with less cytotoxicity at the concentration of 100 and $200 \mu \mathrm{g} / \mathrm{mL}$, respectively. Furthermore, an essential oil prepared from the bud of clove, which contains EU and EU acetate as dominant components, showed melanin inhibition of 50\% and $80 \%$ in B16 melanoma cells at the concentration 


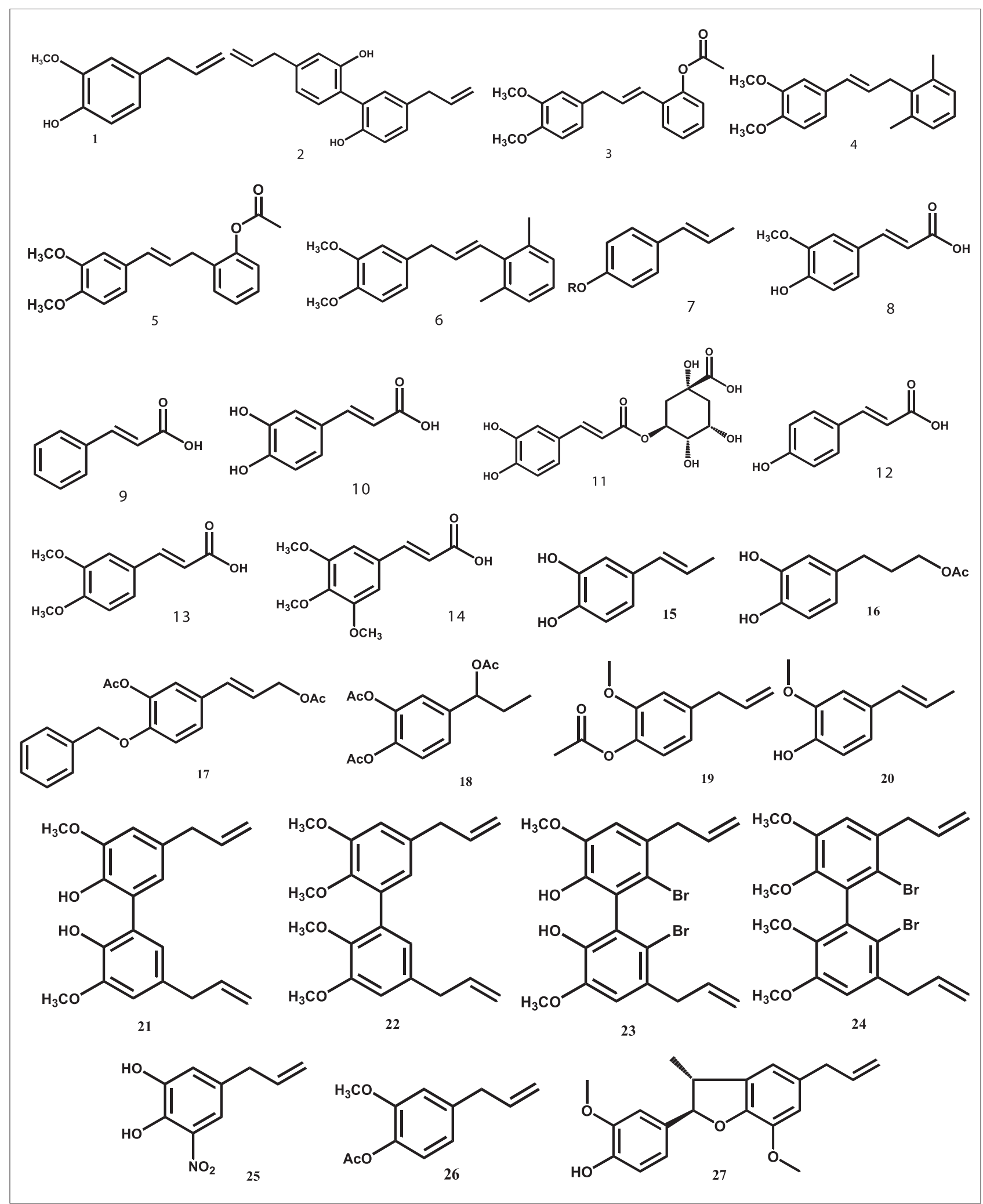

Fig. 1: Phenylpropanoids, eugenol scaffold and its derivatives as anticancer

of 100 and $200 \mu \mathrm{g} / \mathrm{mL}$, respectively [39]. EU and iso EU monomers 20 and their respective $O, O^{\prime}$-dimethyl-dehydrodi EU 21 did not show to inhibit melanoma cells proliferation. Conversely, the dimeric forms (biphenyls) showed some antiproliferative activity which was mild for dehydrodi EU, higher for its $O, O^{\prime}$-methylated 22 form $\left(O, O^{\prime}\right.$-dimethyldehydrodieugenol), and markedly pronounced for the racemic mixture of the brominated biphenyl (6,6'-dibromo-dehydrodieugenol) (S7) 23, being its enantiomeric form $(S) 24$ the most effective compared to the other compounds. Such activity resulted to be selective against tumor cells, without affecting cultured normal human skin fibroblasts. Dose and time dependence curves have been obtained for the enantiomeric form S7-(S). Then, IC50 and minimal effective doses and times have been established for the melanoma cell lines tested. TUNEL and phosphatidylserine exposure assays demonstrated the occurrence 
Table 1: Phenylpropanoids, EU scaffold and its derivatives as cancer activity

\begin{tabular}{|c|c|c|c|}
\hline phenylpropanoids, EU scaffold and its derivatives & Activity/mechanism & Animal/cell line & References \\
\hline EU (Eu) 1 & MMP & & 16 \\
\hline Eu and canola oil & Induced G1/S cell cycle & HCT 116 & 23 \\
\hline \multirow[t]{3}{*}{ Magnolol (bi EU) 2} & AMPK activation & & 24 \\
\hline & DNA Synthetase & & 25 \\
\hline & Ras/Raf-1/Erk & & 26 \\
\hline $\mathrm{Eu}$ & CDK & Mamae xenograph & 28 \\
\hline Eu derivatives $\mathrm{Z}, \mathrm{E}$ isomer & Citotoxicity & MDA-MB-231 & 29 \\
\hline \multicolumn{4}{|l|}{$\mathrm{EU}$ with $\mathrm{Z}$ isomers compound 3 and $4, \mathrm{E}$ isomers 5 and 6} \\
\hline $\mathrm{Eu}$ & MMP 9 & MCF7 & 30 \\
\hline Phenilpropanoide $7+5 \mathrm{Fu}$ & Cell cycle & HeLa & 33 \\
\hline EU 1>ferulic $8>$ cinnamic $9>$ caffeic $10>$ chlorogenic $11>$ p-coumaric & G0/G1; G1/G2 phase & & 34 \\
\hline \multicolumn{4}{|l|}{$12>3,4$-dimethoxycinnamic $13>2,4,5$-trimethoxycinnamic acids 14} \\
\hline Eu+gemcitabine & Bcl2, COX2, IL-1B & & \\
\hline \multicolumn{4}{|l|}{ EU+sulforaphane } \\
\hline EU scaffold (hydrocarvicol) 15, 16, 17, and 18 & Antiproliferative & HeLa & 36 \\
\hline EU and Eu Acetat 19 & Citotoxicity & B16 & 39 \\
\hline \multicolumn{4}{|l|}{ EU, IsoEu 20} \\
\hline \multicolumn{4}{|l|}{$\begin{array}{l}\left(O, O^{\prime} \text {-dimethyl-dehydrodieugenol), 6,6'-dibromo-dehydrodieugenol } 23 \text { its }\right. \\
\text { enantiomeric form }(S) 24\end{array}$} \\
\hline \multirow[t]{2}{*}{$\mathrm{Eu}$} & $\mathrm{E} 2 \mathrm{~F}$ & In vivo & 17 \\
\hline & Cell cycle & UM1205Lu & 41 \\
\hline Eu+honey & & L1210 in mouse & 18 \\
\hline $\mathrm{Eu}$ & ROS & HL-60 & 43 \\
\hline Eu+capsaicin & Caspase 9 dan 3, P53 & & 48 \\
\hline $\mathrm{Eu}$ & $\mathrm{NfkB}$ & Wistar & 49 \\
\hline Eu+methoxyestradiol & G2/M Phase & PC-3, Hep G2 & 52,55 \\
\hline Eu and derivatives & Citotoxicity & DU-145, KB & 53 \\
\hline 5-allyl-3-nitrobenzene-1,2-diol 25 and 4-allyl-2-methoxy-5-nitrophenyl acetate 26 & Citotoxicity & TE-13 & 53 \\
\hline dihydro-eugenol 15, dehydrodiisoeugenol 27, isoeugenol, EU, and bis-eugenol 21 & Citotoxicity & HSG, HGF & 56 \\
\hline
\end{tabular}

ROS: Reactive oxygen species, EU: Eugenol, HGF: Human gingival fibroblasts

of apoptotic events associated with the antiproliferative activity of S7-(S). Cytotoxic activity and apoptosis induced by treating melanoma cells with EU -related biphenyls was partially dependent by caspase activation [40].

Another study conducted that deregulation of E2F1 may be a key factor in EU-mediated melanoma growth inhibition both in vitro and in vivo. Since the E2F transcription factors provide growth for the continuous proliferation of melanoma cells, these results suggest that EU could be developed as an E2F-targeted agent for melanoma treatment [17]. Examination of the mechanism of the anti-proliferative action of EU in the human malignant melanoma cell line, WM1205Lu, showed that it arrests cells in the $\mathrm{S}$ phase of the cell cycle. Flow cytometry coupled with biochemical analyses demonstrated that EU-induced apoptosis. The E2F proteins are a family of transcription factors with an important role in regulating cell cycle progression [41]. It has been shown that deregulated transcriptional activity of the E2F family in autonomously growing melanoma cells provides for continuous proliferation of melanoma cells. Specifically, E2F2 and E2F4 are predominant in actively proliferating melanocytes, melanoma cells, and freshly isolated melanoma tumors.

Anticancer activity of phenylpropanoids, EU scaffold and its derivatives against Leukemia

Leukemia is widely called blood cancer and it is characterized by uncontrolled growth of blood cells produced in the bone marrow. It has estimated that 6020 people $(3,140$ in males and 2,880 in females) will be affected and 1440 people will die of leukemia in 2014 [42]. Jaganathan et al., 2014, were evaluated of honey and one of its phenolic constituent EU against L1210 lymphoid leukemia. The EU treated with intraperitoneal injection to mice could not increase the median survival time (MST) of animals. Further, there was only slight marginal increase in the $\% \mathrm{~T} / \mathrm{C}$ values of EU treated groups. This study limits the use of selected EU against leukemia animal model. Antitumor effect of EU against L1210 leukemia animal model, result showed the
EU displayed nonsignificant anti-leukemic activity compared with the positive control. This result serves as an indicator that the higher phenolic content of EU may not be always a prime factor to promote antitumor effect in leukemia animal model. Further apoptotic activity of EU in certain leukemia cancer cell lines may not correlate with the anti-leukemic effect observed on L1210 animal model [18]. But in the other studied that EU treated HL-60 cells displayed features of apoptosis including DNA fragmentation and formation of DNA ladders in agarose gel electrophoresis. The study observed that EU transduced the apoptotic signal via ROS generation, thereby inducing mitochondrial permeability transition, reducing anti-apoptotic protein $\mathrm{Bcl}-2$ level, inducing cytochrome $\mathrm{c}$ release to the cytosol and subsequent apoptotic cell death. This study demonstrated that ROS plays a critical role in EU induced apoptosis in HL-60, and this is the first report on the mechanism of the anticancer effect of EU [43].

Anticancer activity of phenylpropanoids, EU scaffold and its derivatives against gastric

Gastric cancer can progress through of multistep process from chronic gastritis frequently resulting from Helicobacter pylori infection to gastric atrophy, intestinal metaplasia, dysplasia, and finally to carcinoma [44]. Although differentgenetic and epigenetic alteration involving oncogenes activation, tumor suppressor genes mutations, DNA repair genes, microsatellite instability, loss of heterozygosity have been reported in both esophageal and gastric cancers [45], genetic alterations in TP53 tumor suppressor gene are fundamental events related in both early stage and advanced tumor. p53 mutation is a common event in human cancers which causes defects in apoptosis and makes cancer cells resistant to chemotherapeutic agents [46]. Alterations in p53 occur in gastric carcinoma and it increases in frequency during the course of gastric carcinoma developments [47]. In the presence of p53, capsaicin was a more potent pro-apoptotic agent than EU. However, silencing of p53 significantly apoptosis induced by capsaicin but not that by EU. Western blot analysis of pro-apoptotic markers revealed that as opposed to capsaicin, EU could induce caspase-8 and caspase-3 even 
in the absence of p53. EU was a better apoptotic agent than capsaicin because of its ability to induce the extrinsic pathway of apoptosis in a p53 independent. Loss of function of p53 tumor suppressor gene is implicated in defective apoptotic response of tumors to chemotherapy. Thus, agents which can induce apoptosis irrespective of the cellular p53 status have immense scope for development as potential anticancer agents. Therefore, EU warrants further investigation for its potential use as anticancer agent against p53 defective or null tumors with poor prognosis [48].

Manikandan et al. [49] studied the treatment effect of EU on gastric cancer in Wistar rats caused by N-methyl-N'-nitryl-N-nitrosoguanidine by regarding apoptosis, cancer cell invasion, and angiogenesis as the main indices. They found that EU inhibits cell apoptosis, cancer cell invasion, and cancer angiogenesis by regulating the Bcl-2 protein family, apoptotic protease-activating factor-1 (Apaf-1), cytochrome C, and cysteine aspartic protease, and changes the activity of mesenchymal metalloprotease and the expression of MMP-2, MMP-9, vascular endothelial growth factor (VEGF), VEGF receptor 1, and tissue metalloprotease inhibitor (TIMP-2). MMP, VEGF, and TIMP are important observations indicating tumorigenesis. The same research by Manikandan et al. conducted effects of EU on NF- $\kappa B$ signaling in a rat model of gastric carcinogenesis induced by N-methyl-N'nitryl-N-nitrosoguanidine (MNNG) by analyzing the expression of nuclear factor-kappaB (NF- $\kappa B)$, the NF- $\kappa B$ target genes that promote (e.g., cyclin D1, cyclin B and PCNA) or inhibit (e.g., p53, p21, and Gadd45) cell proliferation and cell survival. MNNG-induced gastric tumors were characterized by NF- $\kappa \mathrm{B}$ activation that correlated with upregulation of IKK $\beta$, and phosphorylation and degradation of I $\mathrm{B} \alpha$. Furthermore, upregulation of cyclins and PCNA with downregulation of p21, p53, and Gadd45 suggested that the proliferative advantage in gastric carcinomas is dependent on elevated constitutive NF- $\kappa B$ activity [50].

Anticancer activity of phenylpropanoids, EU scaffold and its derivatives against prostate

Prostate cancer is the second leading cause of cancer related deaths in men and will account for approximately 28,000 deaths every year with a dramatic increase in incidence with age [51]. The combination of 2-ME (methoxyestradiol) and EU (4-allyl-2-methoxyphenol) as an approach for enhancing anticancerous activities in prostate cancer cells. Combining 2-ME (2) with EU (i) inhibited growth of prostate cancer cells and induced apoptosis at lower concentrations than either single agent alone; (ii) analysis of the data using CI showed CI values of 0.4 indicating strong synergistic interaction; (iii) increased population of cells $\mathrm{G}(2) / \mathrm{M}$ phase by 4.5 -fold ( $\mathrm{p}=0.01$ ); (iv) significantly reduced expression of antiapoptotic protein Bcl-2 and enhanced expression of proapoptotic protein Bax. Combination induced apoptosis was not affected in PC- 3 cells that over-express or lack Bcl- 2 but was associated with loss of mitochondrial membrane potential.

Since 2-ME was well tolerated in phase II try in patients with HRPC; and EU is consumed by humans in the form of spices, the combination of 2-ME with EU may offer a new clinically relevant treatment regimen. Combining these agents may allow ameliorating any adverse effects of either 2-ME or EU alone by reducing their individual concentrations should these two agents be developed for human use [52]. Curative effect of the combination of EU and 2-methoxyestradiol on non-androgen-dependent prostate cancer. They found that this combination could effectively inhibit the proliferation of prostate cancer cells and enhance the expression of apoptosis precursor protein to prevent prostate cancer [50]. Carrasco et al. [53] studied that EU and its derivatives against prostate cancer cells, namely DU145 (androgen-insensitive prostate cancer cells). This examined cancer cells, EU and its derivatives showed cell-growth inhibition activity. The study demonstrated that EU derivatives, such as 5-allyl-3nitrobenzene-1,2-diol 25 and 4-allyl-2-methoxy-5-nitrophenyl acetate 26 , were significantly $(\mathrm{p}<0.001)$ more active than EU, with IC50 values of $19.02 \times 10^{-6}$ and $21.5 \times 10^{-6} \mathrm{~mol} \mathrm{~L}^{-1}$.
Anticancer activity of phenylpropanoids, EU scaffold and its derivatives against other cancer

Furthermore, it has been demonstrated that EU with in vitro study shown that cytotoxic properties of the clove oil and EU, toward human fibroblasts and endothelial cells. Clove oil was found to be highly cytotoxic at concentrations as low as $0.03 \%(\mathrm{v} / \mathrm{v})$ with up to $73 \%$ of this effect attributable to EU. beta-caryophyllene did not exhibit any cytotoxic activity, indicating that other cytotoxic components may also exist within the parent oil [54]. Volatile oils display cytotoxic action toward the human tumor cell lines PC-3 and Hep G2 50 [55]. A derivative of EU, dihydro- EU 27, has been shown to induce apoptosis of MCF [55]. Studies have demonstrated that EU provides protection from chemically induced skin cancer. Maximum cell death and apoptotic cell demise occurred in TE-13 cells within $24 \mathrm{hrs}$ by clove oil at $300 \mu \mathrm{l} / \mathrm{ml}$ with $80 \%$ cell death. In this way, Atsumi and collaborators [56] compared the cytotoxicity of dehydrodiiso EU 28, alpha-di-iso EU 29, iso EU, EU, and bis- EU 30 in a gland tumor cell line (HSG) and normal human gingival fibroblasts (HGF). These compounds against the salivary gland tumor cell line (HSG) and normal HGF were greatest in dehydrodiiso EU 27 and alpha-di-isoeugenol 28, followed by isoeugenol, which showed greater activity than EU [54]. The EU analogs were examined by in vitro model of cancer using KB (oral squamous carcinoma cells) in KB cells of $18.11 \times 10^{-6}$ and $21.26 \times 10^{-6} \mathrm{~mol} \mathrm{~L}^{-1}$, respectively, suggesting that the presence of nitro and hydroxyl groups could be important in the activity of these compounds [55].

\section{CONCLUSION}

This review serves to provide a compiled that EU scaffold as chemoprevention utilizes appropriate pharmacological agents. The antiproliferative and molecular mechanism of EU with scaffold phenylpropanoids and its derivatives can induce apoptosis in various cancer cell lines and animal models. EU has developed as a promising candidate both in in vivo and in vitro studies.

\section{ACKNOWLEDGMENTS}

We sincerely thank Lecture of the doctoral program, Faculty of Pharmacy, University of Indonesia, Indonesia for providing technical support throughout our studies.

\section{REFERENCES}

1. Hanahan D, Weinberg RA. The hallmarks of cancer. Cell 2000;100(1):57-70.

2. Earnshaw WC. Nuclear changes in apoptosis. Curr Opin Cell Biol 1995;7(3):337-43.

3. Vaux DL, Cory S, Adams JM. Bcl-2 gene promotes haemopoietic cell survival and cooperates with c-myc to immortalize pre-B cells. Nature 1988;335(6189):440-2

4. Bonnefoy-Berard N, Aouacheria A, Verschelde C, Quemeneur L, Marçais A, Marvel J. Control of proliferation by Bcl-2 family members. Biochim Biophys Acta 2004;1644(2-3):159-68.

5. Otake Y, Soundararajan S, Sengupta TK, Kio EA, Smith JC, Pineda-Roman M, et al. Fernandes, overexpression of nucleolin in chronic lymphocytic leukemia cells induces stabilization of Bcl-2 mRNA. Blood 2007;109(7):3069-75.

6. Kelly PN, Strasser A. The role of Bcl-2 and its pro-survival relatives in tumourigenesis and cancer therapy. Cell Death Differ 2011;18(9):1414-24.

7. Chresta CM, Arriola EL, Hickman JA. Apoptosis and cancer chemotherapy. Behring Inst Mitt 1996;97:232-40.

8. Chao DT, Korsmeyer SJ. BCL-2 family: Regulators of cell death. Annu Rev Immunol 1998;16:395-419.

9. $\mathrm{Su}$ YC, Ho CL. Composition, in-vitro anticancer, and antimicrobial activities of the leaf essential oil of Machilus mushaensis from Taiwan. Nat Prod Commun 2013;8(2):273-5.

10. Manjamalai A, Grace VM. The chemotherapeutic effect of essential oil of Plectranthus amboinicus (Lour) on lung metastasis developed by B16F-10 cell line in C57BL/6 mice. Cancer Invest 2013;31(1):74-82.

11. Ashour HM. Antibacterial, antifungal, and anticancer activities of volatile oils and extracts from stems, leaves, and flowers of Eucalyptus sideroxylon and Eucalyptus torquata. Cancer Biol Ther 2008;7(3):399-403. 
12. Ralph A, Provan GJ. Phytoprotectants. In: Garrow JS, James WP, Ralph A, editors. Human Nutrition and Dietetics. United Kingdom: Elsevier Limited; 2005. p. 417-24.

13. Medina-Holguín AL, Holguín FO, Micheletto S, Goehle S, Simon JA, O'Connell MA. Chemotypic variation of essential oils in the medicinal plant, Anemopsis californica. Phytochemistry 2008;69(4):919-27.

14. Shefali A, Shilpi A, Shailey A, Shailey S. Anticancer activities of thiosemicarbazides/thiosemicarbazones: A review. Int J Pharm Pharm Sci 2014;6(9):34-41.

15. Shiny G, Kumaran S, Meena C, Pallavi G, Gururagavan M. Docking studies of novel coumarin derivatives as arylamine $\mathrm{N}$-acetyltransferase 2 inhibitors. Asian J Pharm Clin Res 2012;5(1):94-6.

16. Jaganathan SK, Mazumdar A, Mondhe D, Mandal M. Apoptotic effect of eugenol in human colon cancer cell lines. Cell Biol Int 2011;35(6):607-15.

17. Ghosh R, Nadiminty N, Fitzpatrick JE, Alworth WL, Slaga TJ, KumarAP. Eugenol causes melanoma growth suppression through inhibition of E2F1 transcriptional activity. J Biol Chem 2005;280(7):5812-9.

18. Jaganathan SK, Mondhe D, Wani ZA, Supriyanto E. Evaluation of selected honey and one of its phenolic constituent eugenol against L1210 lymphoid leukemia. ScientificWorldJournal 2014;2014:912051.

19. Benencia $\mathrm{F}$, Courrèges MC. In vitro and in vivo activity of eugenol on human herpesvirus. Phytother Res 2000;14(7):495-500.

20. Chogo JB, Crank G. Chemical composition and biological activity of the Tanzanian plant Ocimum suave. J Nat Prod 1981;44(3):308-11.

21. Asha MK, Prashanth D, Murali B, Padmaja R, Amit A. Anthelmintic activity of essential oil of Ocimum sanctum and eugenol. Fitoterapia 2001;72(6):669-70.

22. Ferlay J, Shin HR, Bray F, Forman D, Mathers C, Parkin DM. Estimates of worldwide burden of cancer in 2008: GLOBOCAN 2008. Int J Cancer 2010;127(12):2893-917.

23. Majeed H, Antoniou J, Fang Z. Apoptotic effects of eugenol-loaded nanoemulsions in human colon and liver cancer cell lines. Asian Pac J Cancer Prev 2014;15(21):9159-64.

24. Park JB, Lee MS, Cha EY, Lee JS, Sul JY, Song IS, et al. Magnololinduced apoptosis in HCT-116 colon cancer cells is associated with the AMP-activated protein kinase signaling pathway. Biol Pharm Bull 2012;35(9):1614-20.

25. Lin SY, Liu JD, Chang HC, Yeh SD, Lin CH, Lee WS. Magnolol suppresses proliferation of cultured human colon and liver cancer cells by inhibiting DNA synthesis and activating apoptosis. J Cell Biochem 2002;84(3):532-44.

26. Hsu YF, Lee TS, Lin SY, Hsu SP, Juan SH, Hsu YH, et al. Involvement of Ras/Raf-1/ERK actions in the magnolol-induced upregulation of p21 and cell-cycle arrest in colon cancer cells. Mol Carcinog 2007;46(4):275-83.

27. Steven AN, Javaid I, Anthony BM. Why have breast cancer mortality rates declined? J Cancer Policy 2015;5:8-17.

28. Al-Sharif I, Remmal A, Aboussekhra A. Eugenol triggers apoptosis in breast cancer cells through E2F1/survivin down-regulation. BMC Cancer 2013;13:600

29. Abdel Bar FM, Khanfar MA, Elnagar AY, Badria FA, Zaghloul AM, Ahmad KF, et al. Design and pharmacophore modeling of biaryl methyl eugenol analogs as breast cancer invasion inhibitors. Bioorg Med Chem 2010;18(2):496-507.

30. Baharara J, Ramezani T, Mousavi M, Kouhestanian K. Eugenol suppressed metastasis of breast carcinoma cells and migration by regulation of MMP-9 \& paxilin gene expression. Sch J Agric Vet Sci 2015;2(2B):125-30.

31. Vidhya N, Devaraj SN. Induction of apoptosis by eugenol in human breast cancer cells. Indian J Exp Biol 2011;49(11):871-8.

32. Crosbie EJ, Einstein MH, Franceschi S, Kitchener HC. Human papillomavirus and cervical cancer. Lancet 2013;382(9895):889-99.

33. Hemaiswarya S, Doble M. Combination of phenylpropanoids with 5-fluorouracil as anti-cancer agents against human cervical cancer (HeLa) cell line. Phytomedicine 2013;20(2):151-8.

34. Hussain A, Brahmbhatt K, Priyani A, Ahmed M, Rizvi TA, Sharma C. Eugenol enhances the chemotherapeutic potential of gemcitabine and induces anticarcinogenic and anti-inflammatory activity in human cervical cancer cells. Cancer Biother Radiopharm 2011;26(5):519-27.

35. Hussain A, Priyani A, Sadrieh L, Brahmbhatt K, Ahmed M, Sharma C. Concurrent sulforaphane and eugenol induces differential effects on human cervical cancer cells. Integr Cancer Ther 2012;11(2):154-65.

36. Yadav Y, Owens EA, Sharma V, Aneja R, Henary M. Synthesis and evaluation of antiproliferative activity of a novel series of hydroxychavicol analogs. Eur J Med Chem 2014;75:1-10.

37. Bataille V. Genetic epidemiology of melanoma. Eur J Cancer 2003;39(10):1341-7.

38. Chin L. The genetics of malignant melanoma: Lessons from mouse and man. Nat Rev Cancer 2003;3(8):559-70.

39. Arung ET, Matsubara E, Kusuma IW, Sukaton E, Shimizu K, Kondo R. Inhibitory components from the buds of clove (Syzygium aromaticum) on melanin formation in B16 melanoma cells. Fitoterapia 2011;82(2):198-202.

40. Pisano M, Pagnan G, Loi M, Mura ME, Tilocca MG, Palmieri G, et al. Antiproliferative and pro-apoptotic activity of eugenol-related biphenyls on malignant melanoma cells. Mol Cancer 2007;6:8.

41. Cam H, Dynlacht BD. Emerging roles for E2F: Beyond the G1/S transition and DNA replication. Cancer Cell 2003;3(4):311-6.

42. Available from: http://www.cancer.org/cancer/leukemiachronicmyeloidcml/detailedguide/leukemia-chronic-myeloidmyelogenous-key-statistics.

43. Yoo CB, Han KT, Cho KS, Ha J, Park HJ, Nam JH, et al. Eugenol isolated from the essential oil of Eugenia caryophyllata induces a reactive oxygen species-mediated apoptosis in HL-60 human promyelocytic leukemia cells. Cancer Lett 2005;225(1):41-52.

44. Correa P. A human model of gastric carcinogenesis. Cancer Res 1988;48(13):3554-60.

45. Ong CA, Lao-Sirieix P, Fitzgerald RC. Biomarkers in Barrett's esophagus and esophageal adenocarcinoma: Predictors of progression and prognosis. World J Gastroenterol 2010;16(45):5669-81.

46. Do PM, Varanasi L, Fan S, Li C, Kubacka I, Newman V, et al. Mutant p53 cooperates with ETS2 to promote etoposide resistance. Genes Dev 2012;26(8):830-45.

47. Busuttil RA, Zapparoli GV, Haupt S, Fennell C, Wong SQ, Pang JM, et al. Role of p53 in the progression of gastric cancer. Oncotarget 2014;5(23):12016-26.

48. Sarkar A, Bhattacharjee S, Mandal DP. Induction of apoptosis by eugenol and capsaicin in human gastric cancer AGS cells - Elucidating the role of p53. Asian Pac J Cancer Prev 2015;16(15):6753-9.

49. Manikandan P, Murugan RS, Priyadarsini RV, Vinothini G, Nagini S. Eugenol induces apoptosis and inhibits invasion and angiogenesis in a rat model of gastric carcinogenesis induced by MNNG. Life Sci 2010;86(25-26):936-41.

50. Manikandan P, Vinothini G, Vidya Priyadarsini R, Prathiba D, Nagini S. Eugenol inhibits cell proliferation via NF-kappaB suppression in a rat model of gastric carcinogenesis induced by MNNG. Invest New Drugs 2011;29(1):110-7.

51. Pienta KJ, Smith DC. Advances in prostate cancer chemotherapy: A new era begins. CA Cancer J Clin 2005;55(5):300-18.

52. Ghosh R, Ganapathy M, Alworth WL, Chan DC, Kumar AP. Combination of 2-methoxyestradiol (2-ME2) and eugenol for apoptosis induction synergistically in androgen independent prostate cancer cells. J Steroid Biochem Mol Biol 2009;113(1-2):25-35.

53. Carrasco A, Espinoza C, Cardile V, Gallard OC, Cardona W, Lombardo L, et al. Eugenol and its synthetic analogues inhibit cell growth of human cancer cells. J Braz Chem Soc 2008;19(3):543-8.

54. Prashar A, Locke IC, Evans CS. Cytotoxicity of clove (Syzygium aromaticum) oil and its major components to human skin cells. Cell Prolif 2006;39(4):241-8.

55. Chaieb K, Hajlaoui H, Zmantar T, Kahla-Nakbi AB, Rouabhia M, Mahdouani $\mathrm{K}$, et al. The chemical composition and biological activity of clove essential oil, Eugenia caryophyllata (Syzigium aromaticum L. Myrtaceae): A short review. Phytother Res 2007;21(6):501-6.

56. Atsumi T, Fujisawa S, Satoh K, Sakagami H, Iwakura I, Ueha T, et al. Cytotoxicity and radical intensity of eugenol, isoeugenol or related dimers. Anticancer Res 2000;20(4):2519-24. 